\title{
Veggie Rx: an outcome evaluation of a healthy food incentive programme
}

\author{
Michelle Cavanagh ${ }^{1}$, Janine Jurkowski ${ }^{1, *}$, Christine Bozlak ${ }^{1}$, Julia Hastings ${ }^{1}$ and Amy Klein ${ }^{2}$ \\ 'University at Albany School of Public Health, One University Place, Room 175, Rensselaer, NY 12144-3456, USA: \\ ${ }^{2}$ Capital Roots, Albany, NY, USA
}

Submitted 1 December 2015: Final revision received 14 June 2016: Accepted 29 June 2016: First published online 19 August 2016

\begin{abstract}
Objective: One challenge to healthy nutrition, especially among low-income individuals, is access to and consumption of fresh fruits and vegetables. To address this problem, Veggie Rx, a healthy food incentive programme, was established within a community clinic to increase access to fresh produce for low-income patients diagnosed with obesity, hypertension and/or type 2 diabetes. The current research aimed to evaluate Veggie Rx programme effectiveness.

Design: A retrospective pre/post design using medical records and programme data was used to evaluate the programme. The study was approved by the University of Albany Institutional Review Board and the Patient Interest Committee of a community clinic.

Setting: The study was conducted in a low-income, urban neighbourhood in upstate New York.

Subjects: Medical record data and Veggie Rx programme data were analysed for fifty-four eligible participants. An equal-sized control group of patients who were not programme participants were matched on age, ethnicity and co-morbidity status.

Results: A statistically significant difference in mean BMI change $(P=0.02)$ between the intervention and the control group was calculated. The intervention group had a mean decrease in BMI of $0.74 \mathrm{~kg} / \mathrm{m}^{2}$.

Conclusions: Greater improvement in BMI was found among Veggie Rx programme participants. This information will guide programme changes and inform the field on the effectiveness of healthy food incentive programmes for improving health outcomes for low-income populations.
\end{abstract}

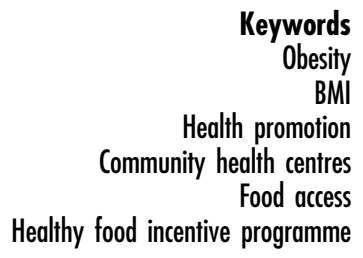

Consuming a balanced diet high in fruits and vegetables has been consistently associated with improved health outcomes and reduced risk for morbidity and mortality ${ }^{(1)}$. At the same time, poor diet or nutrition is a contributing risk factor for overweight and obesity ${ }^{(2-4)}$. Poor dietary practices and being overweight or obese are linked to at least four of the ten leading causes of death - CHD, some cancers, stroke and type 2 diabetes - in the US adult population ${ }^{(5)}$. Yet most Americans eat much less than the recommended amounts of fruits and vegetables; individuals with lower incomes represent population groups least likely to meet the US Department of Agriculture's guidelines for daily servings of fruits and vegetables ${ }^{(1,6,7)}$.

Among New York State residents in 2013, over 25\% were obese and an additional $36 \%$ were overweight ${ }^{(8)}$. The rate of obesity is disproportionately higher among those who earn an annual household income of less than \$US $25000(31.9 \%)^{(8)}$.

According to the Food Choice Process Model $^{(9)}$, people's personal food system in which they make value judgements and choices about what foods they eat is based on where they are in the life course, the influence of personal and social factors, and resources. Personal factors include ideals or standards and expectations by which people evaluate food choices. The social factors include food context or the environmental availability of multiple types of food and their cost. Personal resources such as money, knowledge and skills also influence people's food system. According to this model, multiple influences that affect peoples' personal food system ultimately impact their value negotiations for making food choices and scripts and strategies for recurring food decisions ${ }^{(9)}$. Based on this model, promoting fruits and vegetables as important for health (influencing ideals) and improving access to a wider variety of affordable, quality produce (influencing food context) may increase consumption of fruits and vegetables among low-income populations, thus changing their personal food system to improve immediate and future health ${ }^{(7,9,10)}$.

A growing number of environmental interventions to increase the availability of fresh fruits and vegetables for 
populations with low access are being developed ${ }^{(11-14)}$. Healthy food incentive programmes represent an environmental intervention strategy that aims to improve consumption through changing the food context so that people are able to obtain fresh produce without the cost burden $^{(12-14)}$. These programmes reduce access barriers to fresh produce for populations who experience purchasing difficulties by providing produce coupons. Additionally, when a health-care provider (a person with health-care authority) issues coupons or vouchers (commonly in 'prescription' or coupon/voucher form), they may influence patients' expectations of what fruits and vegetables can do for their health and therefore may influence patients' values related to fruit and vegetable consumption $^{(9)}$. Theoretically, a programme commonly called a 'prescription produce programme' or a 'healthy food incentive programme' ultimately influences patients' food choice process by creating a formalized process for health-care providers to prescribe fruits and vegetables as 'health care' while the coupon for free or lower-cost produce reduces the cost burden ${ }^{(9)}$. Based on the Food Choice Process Model, healthy food incentive programmes have potential to increase the likelihood of healthier eating, which in turn could improve health status such as $\mathrm{BMI}^{(9)}$.

Several healthy food incentive programmes have emerged throughout the USA; notable programmes are found in New York, Connecticut, Massachusetts and California ${ }^{(15,16)}$. One exemplar intervention with a diabetic population was successful in encouraging produce consumption ${ }^{(12)}$. The findings from these programmes support the rationale that if providers prescribe increasing intake of fruits and vegetables as well as offer a way to decrease the economic cost of eating fresh produce, participants will consume more produce which helps lead to improved health outcomes. Researchers have not assessed whether consuming more fruits and vegetables via a healthy food incentive programme intervention leads to specific and measurable health benefits, such as differences in BMI, a measure used in determining relative weight status.

The present study begins to fill this gap in the literature regarding the benefits of a healthy food incentive programme. The Veggie Rx programme was evaluated to determine whether writing prescriptions for fruits and vegetables and improving the ability to purchase fresh produce was effective in reducing patients' BMI.

\section{Participants and methods}

\section{Setting}

The Veggie Rx programme was developed and implemented by Capital Roots in conjunction with the Whitney M Young Jr (WMY) Health Center in Albany, New York. Capital Roots was established in 1975 with the mission to provide access to healthy fresh food and green spaces for all residents of New York's Capital Region with a specific focus on poor and underserved communities ${ }^{(17)}$. Helping to reduce the impact of poor nutrition on public health remains Capital Roots' goal by delivering healthy and fresh produce options via mobile markets and programmes to community members on a regular, weekly schedule. Building upon a previously established relationship with the WMY Health Center, Capital Roots expanded its efforts with the initiation of a fruit and vegetable prescription incentive programme to facilitate and increase fruit and vegetable consumption (E Zimmerman, unpublished results). WMY was a natural partner for Capital Roots because there is overlap in the service populations. While just $13 \%$ of the population residing in the counties served by WMY lives at or below the federal poverty level, approximately $33 \%$ of WMY patients are at or below this threshold ${ }^{(18,19)}$. Further, WMY meets the Health Research and Services Administration's Health Center Program definition of being 'designated to serve medically underserved populations/ areas or special medically underserved populations, ${ }^{(20)}$.

The Veggie Rx programme was funded by a grant from the New York State Department of Health's Hunger Prevention and Nutrition Assistance Program (E Zimmerman, unpublished results). The priority population for the Veggie Rx programme was persons who have low income and therefore are often the most prone to face barriers to accessing fresh produce. Veggie Rx began issuing produce coupons in December 2011 to WMY patients who were classified as obese, hypertensive and/or diabetic. During the initial visit, patients met with the nutritionist at WMY who acted as the programme liaison. She provided information to influence patients' values related to the importance of fruits and vegetables for health and enrolled eligible and interested patients in the programme. Patients were enrolled in the programme using a convenience sample; the nutritionist at WMY enrolled patients she saw in the clinical setting whom she deemed at increased risk as a result of their disease status (the presence of obesity, hypertension and/or diabetes). As long as patients had one of the aforementioned conditions they were considered 'at risk' and the nutritionist enrolled them into the programme as she saw appropriate using her clinical expertise. She issued their first set of Veggie Rx prescriptions. Each prescription coupon booklet contained thirteen coupons, each for one week's worth of produce, \$US 7 in value, which could be redeemed at Capital Roots' Veggie Mobile, a mobile produce market that travels to inner-city neighbourhoods ${ }^{(17)}$. Patients could use a maximum of one coupon per week. If all coupons were redeemed by the end of the 13 weeks, they were eligible to receive another coupon booklet for the next quarter. One of the Veggie Mobile's weekly stops is at WMY Health Center, which helps to increase access to and reduce barriers for Veggie $\mathrm{Rx}$ patients to fill their produce prescriptions. The Veggie Rx programme enables patients to enter and exit the programme at different times. In order to continue 
receiving Veggie $\mathrm{Rx}$ coupons, patients must return to WMY for a routine quarterly appointment with the nutritionist and a primary-care provider.

Of the fifty-four patients included in the programme analysis, $53.7 \%$ were African American, 29.6\% were Caucasian, $3.7 \%$ were biracial and $12.9 \%$ did not have race/ ethnicity documented in their medical records. Eighty-eight per cent of patients were enrolled in Medicare and/or Medicaid health insurance programmes. The remaining $12 \%$ of patients were equally dispersed between enrolling in private health insurance or reporting no insurance coverage.

\section{Design}

A retrospective case-control study design was used to evaluate the Veggie Rx programme by a University at Albany student/faculty team from the School of Public Health. The Institutional Review Board application to analyse existing data was submitted and approved. Before evaluation occurred, a presentation was given to the Patient Interest Committee at WMY in order to grant permission to use their electronic medical records to obtain necessary clinical and demographic patient information.

Data extracted from the Capital Roots redemption logs and the WMY medical records were combined for analysis. It was decided that participants needed to be actively participating in the programme for greater than 1 month to be able to have enough time for measureable weight loss. A total of fifty-four patients who were classified as obese, hypertensive and/or diabetic participated in the programme for a minimum of 5 weeks and had BMI recorded in their medical records at the time of their first and last coupon redemption. These fifty-four patients who met the criteria above and were selected for enrolment in the analysis represent about $30 \%$ of the total number of patients enrolled in the Veggie $\mathrm{Rx}$ programme at that time. A sample size of fifty-four was more than sufficient to achieve greater than $80 \%$ power for the study analysis. A control group of fifty-four WMY patients not enrolled in the Veggie Rx programme, sampled by querying the WMY electronic medical record system, were matched with the study group on ethnicity, age and co-morbidity status (obesity, hypertension, and/or diabetes) to account for non-intervention effects.

\section{Measures}

\section{BMI}

Data on patients' BMI were extracted from de-identified electronic medical records supplied by WMY. During the patients' quarterly visits, routine measures such as weight and height were taken, and BMI was calculated and recorded in the patients' medical records.

\section{Coupon redemption}

Veggie $\mathrm{Rx}$ coupon redemption data were collected from coupon redemption logs provided by Capital Roots. Each booklet of coupons that belonged to a patient had a specific identification number and furthermore each individual coupon within the booklet was also numbered. From these records it could be determined when and for what duration of time patients had redeemed coupons. The mean number of coupons redeemed among the fiftyfour included programme participants was 22, with a range of 5-87 redemptions. Redemptions did not have to be for consecutive weeks to be included in the analysis.

\section{Data analysis}

Descriptive statistics, including frequencies and percentages, were conducted to determine the sample's background characteristics. A two-sample $t$ test was performed to assess whether the mean BMI values of the control and intervention groups were statistically different pre and post intervention. The two-sample $t$ test was also used to assess whether the calculated change in BMI from two points in time was statistically different between the control and intervention groups. For the comparison population, an equivalent amount of time was used in order to extract 'starting' and 'ending' dates for BMI. For example, if the Veggie Rx patient had a starting BMI taken in January 2013 and then had an ending BMI in June 2013, we matched the control's recorded BMI from January 2013 as the starting BMI and the June 2013 BMI as the ending BMI. The average duration between measures of BMI was 18 months. All data analyses in the current paper were generated using the statistical software package SAS version 9.4 .

\section{Results}

Significant pre-post intervention differences in BMI were observed for Veggie Rx participants. Table 1 illustrates the BMI of the Veggie Rx case and control groups both pre and post intervention. The BMI of controls increased slightly during the intervention period, whereas the BMI of cases decreased. Table 2 illustrates a significant outcome of the two-sample $t$ test $(P=0 \cdot 02)$, a value which allowed for the null hypothesis to be rejected; therefore, the change in BMI of the Veggie Rx group was significantly different from the change in BMI of the control group. The Veggie Rx case group members experienced a mean decrease in BMI of $0.74 \mathrm{~kg} / \mathrm{m}^{2}$, whereas the non-Veggie $\mathrm{Rx}$ control group members reported a mean increase in BMI of $0.35 \mathrm{~kg} / \mathrm{m}^{2}$.

\section{Discussion}

Study findings indicate that individuals who consistently participated in a healthy food incentive programme for at least five non-consecutive weeks experienced positive changes in body weight status, as indicated by the statistically significant decrease in BMI, whereas the matched control group experienced a slight increase in BMI. 
Table 1 Mean BMI of cases (intervention participants) and controls, pre and post intervention; Veggie Rx healthy food incentive programme conducted in a low-income, urban neighbourhood in Albany, New York, USA

\begin{tabular}{|c|c|c|c|c|c|}
\hline \multirow[b]{2}{*}{ Group } & \multirow{2}{*}{$\begin{array}{l}\text { Pre or post } \\
\text { intervention }\end{array}$} & \multirow[b]{2}{*}{$n$} & \multicolumn{2}{|c|}{ BMI $\left(\mathrm{kg} / \mathrm{m}^{2}\right)$} & \multirow[b]{2}{*}{ Test statistic ( $t$ value) } \\
\hline & & & Mean & SD & \\
\hline \multirow[t]{2}{*}{ Cases } & Pre & 54 & $40 \cdot 02$ & $10 \cdot 62$ & $27 \cdot 68^{\star *}$ \\
\hline & Post & 54 & 39.27 & $10 \cdot 84$ & $26 \cdot 26^{* *}$ \\
\hline \multirow[t]{2}{*}{ Controls } & Pre & 54 & 37.41 & $8 \cdot 14$ & $33 \cdot 79^{\star \star}$ \\
\hline & Post & 54 & 37.76 & 8.52 & $32.56^{\star *}$ \\
\hline
\end{tabular}

${ }^{\star *} P<0.0001$.

Table 2 Mean change in BMI (post-intervention mean - preintervention mean) of cases (intervention participants) and controls; Veggie $R x$ healthy food incentive programme conducted in a lowincome, urban neighbourhood in Albany, New York, USA

\begin{tabular}{lcccc}
\hline & & \multicolumn{2}{c}{ Change in BMI $\left(\mathrm{kg} / \mathrm{m}^{2}\right)$} & \\
\cline { 3 - 4 } & $n$ & Mean & SD & $\begin{array}{c}\text { Test statistic } \\
(t \text { value })\end{array}$ \\
\hline Cases & 54 & -0.74 & 2.72 & $-2.43^{\star}$ \\
Controls & 54 & 0.35 & 1.91 & \\
\hline
\end{tabular}

${ }^{*} P<0.05$.

A similar study conducted among Aboriginal children in Australia did not find improvements in $\mathrm{BMI}^{(21)}$. However, the children may have had greater nutritional challenges and very likely had less control over their food preparation and availability (children are dependent on adults for food availability, preparation and role modelling) compared with our sample of US urban adults ${ }^{(21)}$. Our evaluation provides evidence supporting the potential for healthy food incentive programmes to contribute to positive health outcomes among adults.

The health benefits of consuming fruits and vegetables are evident, and environmental change such as increasing access to fresh fruits and vegetables is a promising community-based strategy for obesity prevention ${ }^{(11,22)}$. Our findings underscore the importance of focusing on the important environmental intervention leverage points to support healthy lifestyles specifically appropriate for low-income populations. Having health providers reinforce messages about the benefits of increased fruit and vegetable consumption and provide easier access points to purchase produce are two strategies that influence the food choice process for nutritional gains in modest behaviour changes ${ }^{(9,15,16)}$. Further, modest reduction or even stabilization of BMI can stabilize metabolic syndrome components, therefore slowing progression of indicators of chronic disease ${ }^{(23-25)}$. Although a review by the US Preventive Services Task Force did not find enough evidence for behavioural change interventions related to obesity for long-term outcomes (such as mortality and CVD) for adults, it did find that the most effective obesity prevention interventions to improve weight status (with an average weight loss of $4-7 \mathrm{~kg}$ ) and other risk factors for adults are of high intensity and comprehensive in nature. The Task Force's recommendations include addressing barriers to change and improving diet or nutrition - two facets of a larger behavioural intervention that Veggie Rx may $\operatorname{address}^{(4)}$.

Limitations of the present study represent inherent aspects of secondary data analyses and the retrospective evaluation design. For example, data were extracted from medical records which were not designed for evaluation purposes. Another limitation is that missing data also contributed to the small sample size, which decreased the precision of some parameter estimates. Evaluating changes in chronic disease measures, such as $\mathrm{HbA}_{1 \mathrm{c}}$, would have been ideal, but we were unable to control for medication type and duration, which would make the use of these variables nefarious. Also, because the evaluation was retrospective, existing medical data are not supported by additional process or outcome evaluation measures. Finally, patients were not randomly selected by the provider; therefore there is the possibility for intervention selection bias of pre-existing unmeasured group differences between the study's intervention and control groups. Patients who volunteered to participate in the programme may have been more motivated to change behaviour and/or they may have had fewer barriers to participation that may be related to behaviour change compared with those who did not participate ${ }^{(26)}$.

Despite the limitations noted, our study is among the first to examine whether a healthy food incentive programme can influence a modest change in body weight status in individuals who reside in a community environment with low food access. The study findings also offer timely information relevant to public health practice. Healthy food incentive programmes, such as Veggie Rx, are continuing to emerge as a promising strategy to influence the food choice process to increase fruit and vegetable consumption among individuals at greatest risk of disease, overweight and obesity, and lacking the economic resources to make health-enhancing dietary choices. Additional research should be conducted to determine the effectiveness of similar interventions with larger low access populations, as well as examine social and cultural factors relevant to healthy food incentive programme evaluations. In addition, 
future studies might examine other health status indicators, such as improvement in $\mathrm{HbA}_{1 \mathrm{c}}$, reduction in metabolic syndrome symptoms, decreased blood pressure and other cardiovascular-related outcomes, while controlling for medications and other potential confounding factors in order to unpack the many complex observations about behavioural responses to food access programmes. Another recommended area for future research is to explore the health outcomes and food consumption pattern changes for all members of the participant's household because it is conceivable that by providing fresh fruits and vegetables to one member of a household, all the members may benefit.

\section{Conclusion}

In conclusion, increasing the consumption of fruits and vegetables for everyone is a worthy goal. However, it is particularly important among populations where access to healthy food is scarce or non-existent. Reversing the poor health outcomes of preventable diseases is possible with interventions that are focused and implemented in consideration of important environmental factors ${ }^{(27,28)}$. The current study demonstrated that implementing healthy food incentive programmes in partnership with a local health clinic and a community-based organization addressing food access issues proved a worthy pursuit, especially in consideration of lowering BMI scores in the short term. Promising interventions in low-income communities focused on fresh fruit and vegetable access are important to improve community health indicators and reduce the devastating trends of disease mortality.

\section{Acknowledgements}

Acknowledgements: The authors thank Capital Roots, specifically Amy Klein, E.J. Krans and Will Malcom, and WMY Health Center, including David Shippee, Elyn Zimmerman and the Board of Directors, for providing access to the Veggie Rx programme data. Financial support: This research received no specific grant from any funding agency in the public, commercial or not-for-profit sectors. Conflict of interest: The authors declare no conflicts of interest. Authorship: M.C. conducted the analysis and was the lead author on the manuscript. J.J. mentored M.C. and participated in all aspects of the evaluation and writing of the manuscript. C.B. and J.H. participated in developing the concept of the paper, added sections to the paper and participated in the revisions. A.K. is the Executive Director of Capital Roots and oversaw the Veggie Rx programme, and proofed early versions of the paper. Ethics of human subject participation: The study was approved by the University of Albany Institutional Review Board and the Patient Interest Committee at WMY.

\section{References}

1. Bowman S (2007) Low economic status is associated with suboptimal intakes of nutritional foods by adults in the National Health and Nutrition Examination Survey 1999-2002. Nutr Res 27, 515-523.

2. Corral I, Landrine H, Hao Y et al. (2012) Residential segregation, health behavior and overweight/obesity among a national sample of African American adults. J Health Psychol 17, 371-378.

3. Wang Y \& Beydoun MA (2007) The obesity epidemic in the United States - gender, age, socioeconomic, racial/ethnic, and geographic characteristics: a systematic review and meta-regression analysis. Epidemiol Rev 29, 6-28.

4. Moyer VA (2012) Screening of obesity in adults: US Preventive Services Task Force recommendation statement. Ann Intern Med 157, 373-378.

5. US Department of Health and Human Services (2010) The Surgeons General's Vision for a Healthy and Fit Nation. http://www.ncbi.nlm.nih.gov/books/NBK44656/\#background. s5 (accessed March 2015).

6. Robinson T (2008) Applying the socio-ecological model to improving fruit and vegetable intake among low-income African Americans. J Community Health 33, 395-406.

7. Foltz JL, Harris DM \& Blanck HM (2012) Support among US adults for local and state policies to increase fruit and vegetable access. Am J Prev Med 43, 3 Suppl. 2, S102-S108.

8. New York State Department of Health (2013) Overweight and Obesity: New York State Adults, 2013. BRFSS Brief no. 1502. https://www.health.ny.gov/statistics/brfss/reports/docs/1502_ brfss_overweight_and_obesity.pdf (accessed April 2016).

9. Sobal J \& Bisogni A (2009) Constructing food choice decisions. Ann Behav Med 38, Suppl. 1, S37-S46.

10. Dauchet L, Amouyel P, Hercberg S et al. (2006) Fruit and vegetable consumption and risk of coronary heart disease: a meta-analysis of cohort studies. J Nutr 136, 2588-2593.

11. Khan L, Sobush K, Keener D et al. (2009) Recommended community strategies and measurements to prevent obesity in the United States. MMWR Recomm Rep 58, 1-26.

12. Freedman DA, Choi SK, Hurley T et al. (2013) A farmers market at a federally qualified health center improves fruit and vegetable intake among low-income diabetics. Prev Med 56, 288-292.

13. Herman DR, Harrison GG, Afifi AA et al. (2008) Effect of a targeted subsidy on intake of fruits and vegetables among low-income women in the Special Supplemental Nutrition Program for Women, Infants, and Children. Am J Public Health 98, 98-105.

14. Friedman DB, Freedman DA, Choi SK et al. (2013) Patient communication and role modeling related to patients' perceptions and use of a federally qualified health center-based farmers' market. Health Promot Pract 15, 288-297.

15. Fresh Approach (2013) Veggie Rx Program Report. http:// freshapproach.org/veggie-rx/veggierx-program-report-2013/ (accessed March 2015).

16. Wholesome Wave (2012) Wholesome Wave's Fruit and Vegetable Prescription Program: FVRx ${ }^{\Theta} 2012$ Program Report. http://www.wholesomewave.org/wp-content/uploads/2014/07/ FVRx-Report.pdf (accessed March 2015).

17. Capital Roots (2013) Veggie RX. http://www.cdcg.org/ programs/veggie/veggierx/ (accessed March 2015).

18. US Census Bureau (2009-2013) State and County Quick Facts. http://quickfacts.census.gov/qfd/states/36/36001.html (accessed March 2015).

19. Whitney Young Heath (2012) About Whitney M. Young, Jr. Health Center, Inc. http://www.wmyhealth.org/about-us/ news/2015/5/7/whitney-young-health-open-health-centerwatervliet/ (accessed March 2015). 
20. Health Research and Services Administration (2016) Health Center Program Requirements. http://www.bphc.hrsa.gov/ programrequirements/index.html (accessed April 2016).

21. Black AP, Vally H, Morris PS et al. (2013) Health outcomes of a subsidised fruit and vegetable program for Aboriginal children in northern New South Wales. Med J Aust 199, 46-50.

22. Van Duyn MA \& Pivonka E (2000) Overview of the health benefits of fruit and vegetable consumption for the dietetics professional: selected literature. J Am Diet Assoc 100, 1511-1521.

23. Lloyd-Jones DM, Liu K, Colangelo LA et al. (2007) Consistently stable or decreased body mass index in young adulthood and longitudinal changes in metabolic syndrome components. Circulation 115, 1004-1011.

24. Hill J (2009) Can a small-changes approach help address the obesity epidemic? A report of the Joint Task Force of the American Society for Nutrition, Institute of Food Technologists, and International Food Information Council. Am J Clin Nutr 89, 477-484.

25. Eckel R \& Krauss R (1998) American Heart Association call to action: obesity as a major risk factor for coronary heart disease. Circulation 97, 2099-2100.

26. Larzelere RE \& Kuhn BR (2004) The intervention selection bias: an underrecognized confound in intervention research. Psychol Bull 130, 289-303.

27. Sallis J \& Glanz K (2009) Physical activity and food environments: solutions to the obesity epidemic. Milbank $Q$ 87, 123-154.

28. Davison KK, Jurkowski JM \& Lawson HA (2013) Reframing family-centred obesity prevention using the Family Ecological Model. Public Health Nutr 16, 1861-1869. 